\title{
ESTIMATION OF PROBABLE HEALTH LOSSES IN BIOLOGICAL ATTACK WITH NON-CONTAGIOUS AGENTS, BY MATHEMATICAL EPIDEMIOLOGY
}

\author{
Viorel ORDEANU, Ph.D., \\ Col. (ret.) Prof. MD SR, “Titu Maiorescu” University, Bucharest, Romania. \\ E-mail: ordeanuviorel@yahoo.com \\ Lucia Elena IONESCU, Ph.D., \\ “Cantacuzino" National Military Medical Institute for Research-Development, Bucharest, \\ Romania. E-mail: ionescu.lucia@gmail.com
}

\begin{abstract}
In the case of attack with CBRN Weapons of Mass Destruction, the use of biological warfare agents is likely to amplify the effect on the living force, in order to infect, lethal or nonlethal, as many enemy as possible. The military medical service must be able to prevent, diagnose, treat and recover all affected military and the civilian population in the area. Health losses must be recovered in their entirety. Mathematical modeling of the epidemic induced by biological attack is useful for planning the forces and means of the military medical service, for medical planning the offensive or defensive operation, logistics and human resources needed for medical support and replacement. The estimates resulting from the calculations according to the formulas recommended in the specific NATO documents allow the optimization of the medical and non-medical countermeasures for the liquidation of the consequences of the biological attack.
\end{abstract}

Keywords: biological attack; probable health losses; biological warfare agents; mathematical modeling; medical operational planning.

\section{Introduction}

Biological attack is a reality of the contemporary world. The use of living pathogens has been used since Antiquity for the disease of humans, animals and/or plants, with certain specific objectives. But an intentionally provoked epidemic is likely to spread, get out of control and become a pandemic or create a biological crisis. Biological warfare agents (BWA) are classified into living agents (bacterium and viruses) and non-living agents (toxins) and are listed in the North Atlantic Treaty Organization (NATO) documents STANAG Med and CBRN.

For effective countermeasures it is necessary to estimate as accurately as possible, by mathematical epidemiological calculations, health losses (contaminated, infected, sick people) and total losses (deaths) to quantify the epidemic, in order to prepare the necessary forces and means and eliminate the consequences of biological attack, by medical and non-medical countermeasures.

Specific NATO terms are: "WIA" (wounded in action), namely injured in battle, "KIA" (killed in action), namely dead in battle, "DOW" (died of wound) meaning dead later due to injury or illness in battle, as opposed to the dead and wounded by accidents or the ordinary sick people. 
STRATEGIES XXI International Scientific Conference

The Complex and Dynamic Nature of the Security Environment

\section{Health losses}

Due to the particular conditions in the theater of operations (TO) in case of a biological attack, effects could appear on the military, their fighting and work capacity could be reduced and it is possible that the health losses are registered: sick, wounded, shipwrecked, intoxicated, irradiated, stressed, etc. who can no longer fulfill their mission.

The medical service must be able to prevent, diagnose, treat and recover all soldiers in this situation, and as far as possible for the civilian population in the area. Health losses must be recovered almost entirely for combat, for work or at least for life. The total human losses are represented in addition by: dead, missing, prisoners, etc.

The severity of diseases and injuries is in principle classified into six severity levels according with North Atlantic Treaty Organization (NATO) Planning Guide for the Estimation of CBRN Casualties- AMedP-8(C) (2010):

1. Severity level 0 (no observable effect) = unobservable effects, asymptomatic, although the person has been exposed to harmfull emission (agent, effect), is contaminated or even infected, but shows no symptoms; the military continues his mission;

2. Severity level $1($ Mild $)=$ the patient has (objective) signs and (subjective) symptoms but can take care of himself (self-said) or unqualified people (mutual aid) on the spot or at the injured meeting point and can continue his mission;

3. Severity level 2 (Moderate $)=$ shows obvious signs and symptoms, which require first aid (paramedics) at the medical point of the unit, sometimes requires medical evacuation and sometimes the mission cannot be continued;

4. Severity level 3 (Severe) $=$ shows signs and symptoms that endanger his life, an acute illness that requires hospitalization ROL 1 (qualified medical aid), the treatment may cure him or not; the military cannot continue the mission;

5. Severity level 4 (Very severe $)=$ the signs and symptoms are very serious, the person would not survive in the absence of specific medical care in the hospital ROL 2 (specialized medical aid), the soldier is in danger of death; he cannot continue his mission;

6. Severity level 5 (Extreme severe) $=$ includes severely wounded or sick, who will be evacuated to ROL 3 hospital or dying soldiers, who are no longer considered for battle planning and are managed according to NATO AMedP-8(C).

Depending on the situation, the medical evacuation will be done "by itself" (with own means) or "to itself" (with specialized MedEvac means) in successive stages or directly on destinations (medical competencies), if necessary with means of road transport, railway, naval, air or by any other means. The injured and the sick who present an emergency will have on them, in a visible place, a standard medical file that also specifies the emergency category, with a color code.

Health losses are numerically in the form of a pyramid: most people are healthy or seemingly healthy and form the basis of the pyramid, then we have the 6 levels, descending, and the top of the pyramid is represented by the wounded/deceased patients.

It is generally considered that losses below $10 \%$ do not significantly reduce combat capability (the principle of the Romanian Armed Forces of "decimating" troops fleeing the battlefield). But losses, both of health nature and total, affecting more than half of the troops require the immediate replacement of the entire unit and withdrawal to a recovery area. The Romanian Armed Forces had this situation twice at the operational level, due to the cholera epidemics: in Balkan War II and in the World War I. These were medically solved by the teams of prof.dr. Ioan Cantacuzino using as means cholera vaccination, quarantine, and other medical measures. (Ordeanu Viorel, 2021). 
It should be noted that the evolution of an epidemic and the health losses it causes are somewhat similar to troops and the civilian population, or to natural epidemics or those caused by biological attack. But the results are variable for public health depending on the pathogen, dissemination, receptivity of the population, the effectiveness of individual and collective protection, treatment and health logistics.

\section{The biological attack}

The existing conditions in TO favor the appearance of infectious-contagious diseases and epidemics. In all wars there were more sick people than wounded and more died of infectious diseases than dead in battle, including in the World War I. But in World War II, almost all military health services applied adequate medical countermeasures and there were no major epidemics, except those caused intentionally. The intentional illness of the enemy with infectious-contagious diseases has been known for a long time, even before the discovery of microbes. Currently, "biological warfare" is well-founded for offensive and defensive, tactical, operational and strategic purposes, with lethal or disabling effect, because it is the cheapest (calculated in dollars/victim) and destroys only the living force, leaving weapons and technique in working condition. (Ordeanu V., Andries A.A., Hincu. 2008; Ordeanu, V., Necsulescu. M., Ionescu, L.E., Popescu, D.M., Bicheru, S.N., Dumitrescu, G.V., Hertzog, R.G. 2008)

The intentional spread of living pathogens can be catastrophic in time of war, and disease and death affect troops and the civilian population. But they can also spread to the person who triggered the biological attack, and if they get out of control, a pandemic can occur. This was also the main reason why biological attack was banned by the Geneva Convention (BTWC 1972). (https://Www.un.org/disarmament/biological-weapons). But the methods and techniques of biological warfare have been taken over by terrorist organizations for actions of bioterrorism and biocrime. In the case of natural infectious-contagious biological agents or BWA, there is the same risk of mass spread, out-of-control, biological crisis and finally pandemic, as the natural COVID-19 epidemic is now underway. As a result, international law prohibits any research into offensive biological weapons and/or living or non-living biological agents capable of causing mass disease. But it is believed that the Great Powers, which have nuclear weapons (permitted by international law) could use the other WMD (prohibited by international law) because they can not be prevented from doing so. (Ordeanu V. \& colab. 2012, 978-973).

Biological casualty is any person who becomes ill, is injured or dies as a result of exposure to biological agents or combined injuries. The biological attack is more insidious than other chemical, biological, radiological and nuclear (CBRN) weapons of mass destruction (WMD) attacks due to the extremely small amounts of infectious or toxic material affecting personnel. Unlike chemical warfare agents (CWAs), the infectious cloud is invisible, colorless, odorless, tasteless, does not alert organoleptically, and instrumental detection is late and nonspecific (regardless of what is written in the manufacturer's leaflet). The comparison of the dose of exposure to CWA and BWA is presented in table no. 1. The infectious doses are presented in table no. 1 (adaptation after AMedP-8(C)).

Table no. 1: Comparison of exposure factor EFn, $\mathrm{t}$

\begin{tabular}{|l|c|c|}
\hline Activity level & CWA & BWA \\
\hline Light & 1 & 15 liters of air/min \\
\hline Moderate & 2 & 30 liters of air/min \\
\hline Heavy & 5 & 75 liter of air/min \\
\hline
\end{tabular}


STRATEGIES XXI International Scientific Conference

The Complex and Dynamic Nature of the Security Environment

The methods of estimating the victims of WMD CBRN attacks are different depending on the agent(s) involved and the scenario, but are based on NATO recommendations. From a medical-military point of view, the typical situation is applied at the level of a Large Operational Unit, for example the Infantry Brigade, with different scenarios, depending on the tactical, operative or strategic situation. The NATO AMedP-8(C) Manual presents calculations for 11 CBRN agents: 3 CWA, 3 RWA and 5 BWA, most likely to be used as a model for other agents with similar behavior. Calculation methods for individual dose, dosage, magnitude of damage after exposure to CBRN agents, etc. are described.

The application of the methodology offers the ability to estimate the number of victims over time (dynamics per day): before the disease manifests itself, the incubation period, the incidence of injuries and the degree of severity. The results help military planners, staff officers, medical service, logisticians and commanders to allocate and/or demand adequate quantity and quality forces and means, transport of patients, evacuation of formations, supply and replenishment of stocks of sanitary-pharmaceutical and logistical materials, as well as facilities for decontamination of patients, triage, treatment, specific hospitalization, etc.

The methodology is primarily needed for planning, but can also be useful for real situations if it is based on real-time reported data. But, like any probabilistic calculation, it does not apply to individual cases for diagnosis, prophylaxis and/or treatment. Each epidemiological event has its own unique features and a dynamic multifactorial evolution that is difficult to predict. In the future, it would be possible to estimate through Artificial Intelligence (AI) programs based on previous experience and on modeling the current evolution.

From a medical-military point of view, aerosol dispersion attack (the most effective WBA dissemination technique) with anthrax spores or toxins, although causing mass epidemic diseases, is not considered contagious, unlike the other listed WBAs.

This methodology also includes the information needed to estimate the acute human response to non-contagious WBAs and their effects. It is obvious that the set of parameters cannot be exhaustive, and if other WBAs or any other pathogenic biological agents are used concomitantly or successively in association, or in combined attacks with WCA and/or WRA etc. the disease can be significantly potentiated.

In order to be applied, the methodology must somewhat simplify the reality, so it does not take into account the combined attacks, opportunistic infections, overlap with natural epidemics, living conditions, mental stress and other factors that influence the infectious disease. There are not taken into account: civilians of any kind, detainees, prisoners and missing persons, but only the personnel of the respective unit, and all the others are "collateral losses". Due to the particular complexity of the effects of biological attack, the examples are limited to biological attack scenarios with bacterium (in vegetative or sporulated form), with viruses or toxins, by aerosolization on a large operational unit with its units and subunits, with the military spread in different locations (icon).

The declaration as sick, injured or dead people is made according to the criteria established by the NATO, which concerns victims, as follows:

a) Military killed in mission = KIA or prompt fatality or killed individual in action;

b) Military wounded in combat = WIA or wounded individual in action, includes all types of injuries: penetrating and non-penetrating wounds, contusions, fractures, burns, crushing, infectious diseases, intoxications, asphyxiation, irradiation and any effects of conventional or unconventional weapons or CBRN agents;

c) Military wounded or sick deceased $=$ DOW or died of wounds, delayed fatality meaning any death of a victim who dies as a result of a wound or disease acquired in battle. (NATO AMed-8(C), 4). 
The methodology does not take into account the change in time of the severity level of the disease (evolution). The main input data for the application of the methodology are:

1. Estimating the CBRN environment, agent or effect present in the physical environment in which the military interacts during the attack; it is based on external information sources: CBRN defense subunits, medical teams, CBRN risk prediction models, etc.

2. Development of the scenario, the geographical position of the military according to time, individual physical protection (mask, equipment) and/or collective (vehicles, buildings, shelters) and physiological factors (physical effort, respiratory flow, etc.).

The scenario requires the characterization of the CBRN environment, the initial exposure, the amount of agent and the effects associated with each subunit, the time and severity of the disease in dynamics. For biological agents, the human response to exposure is estimated, separately for contagious and non-contagious agents, in order to estimate the subsequent evolution of diseases.

The methodology estimates the victims (health losses) according to four main parameters:

1. Population at risk (PAR), respectively the number of soldiers actually exposed;

2. The disease rate, namely the percentage expression in the PAR of the new KIA, WIA and DOW cases;

3. The profile of the disease, which shows how many new cases evolve over time;

4. The flow of victims characterizes the change in the classification of patients (for example from WIA to DOW).

\section{Limitations of applying mathematical methodology}

The limitations depend on the input data, the level of uncertainty, the overestimation or underestimation of the effects, and the degree of impact of the approximations is unknown. The additional errors are attenuated by the minus errors and the result is close to the average of the real values, so the estimation presents a reasonable relativity.

The methodology assumes that all soldiers have a good state of health, without preexisting diseases or poor physiological conditions or other factors that increase susceptibility to alter the body's response or contribute to potentiating risk factors, which would lead to underestimation of casualties. This methodology does not apply to civilians, because they are more susceptible to CBRN agents: they do not have special equipment, they do not have training, they do not have specialized medical assistance. For some CBRN agents, this methodology cannot serve as a model for medical countermeasures, but only for calculating the total losses that will reduce the unit's combat capability. A particular situation is presented by the post-exposure prophylaxis in the chemical attack: the use of the self-injection syringe (with atropine, oxime, etc.) temporarily reduces the fighting capacity of the military, but increases the survival. The methodology does not include medical treatment, so mortality is calculated in its absence, as a standard situation. It is considered if the sick are to be treated, the number of dead decreases and the number of sick increases. But it is not possible to estimate precisely who will get sick and how severe or if he will die, but only the total number of illnesses in the time interval. (NATO AMed-8(C), 8)

Neither the recovery of the patients in time for their return to battle is calculated, because the duration of the disease cannot be predicted accurately, nor the results of the treatment. It also does not take into account the psychological effects of battle stress that can affect some staff, which will need medical care.

\section{Assumptions (initial presumptions) in using the methodology}

The presented mathematical methodology assumes, in accordance with NATO doctrine, that all biological agents provided in the scenarios are aerosolized, so they are inhaled and 
STRATEGIES XXI International Scientific Conference

The Complex and Dynamic Nature of the Security Environment

retained in the respiratory tract, because it is the most effective way of biological attack. It is fast, uniform, covers a large area, so a maximum number of potential victims, and what remains in the air will deposit and contaminate the soil and objects in the area, which will become secondary sources of contamination.

The human response is considered to be at full dose exposure to the CBRN agent, but the latency period is variable depending on the individual, especially for the biological agents. It is considered that the reaction of the organism exposed to biological agents can be mathematically modeled according to the probability of the dose/disease or death relationship, with a time distribution of the incubation period and the duration of the symptomatic disease. The mathematical distribution of the duration of the disease differs in survivors and nonsurvivors, and the period of the individual's illness is divided into stages, depending on the level of severity. These simplifications and generalizations of the infectious process (which in reality is complex and multifactorial) allow the practical estimation of the severity in time of the infectious disease, namely the dynamics of the effect. It is believed that the biological agent infects all exposed people, but to varying degrees, from subclinical (asymptomatic) to lethal. The methodology includes the infectivity submodel which describes the relationship between the inhaled dose and the probability of disease, respectively the "infectious dose" in living microorganisms and the "effective dose" in toxins, as well as the severity of the disease. (NATO AMed-8(C), 12-13)

Prophylaxis, in this methodology, is considered to be applicable to infectious diseases caused by non-contagious biological agents in whom there is a vaccine, (for example, anthrax) as an optional parameter in the scenario. The inclusion of prophylaxis in the calculation may give underestimated results, as it does not take into account the individual reactivity and the infectious dose. For other biological agents the methodology does not take into account prophylaxis, if there is no effective and/or available vaccine. (NATO AMed-8(C), 12-13)

\section{Use of methodology}

The methodology for mathematical estimation of health and total losses in biological attack is used by NATO for training and medical, logistical, operational, personnel management planning. (NATO AMed-8(C), 16)

Medical planning, by estimating cases, identifies the medical requirements for each "medical role" separately: drugs, medical devices, type of beds, staff specialty (AMedP-7, STANAG 2478, and AJP-4.10).

Logistics planning determines the medical and non-medical logistical requirements that are necessary for the management of CBRN pathology, with the supply and resupply of specific materials (AJP-4).

Operational planning estimates the ability to evaluate the performance of actions, including parameters such as: health losses, total human losses, individual and collective physical protection, necessary medical countermeasures and even avoiding the operation. (AJP-3).

Personnel planning estimates the need for replacement personnel for CBRN victims (sick and deceased) (AJP-4.10).

The methodology for estimating the effects of biological attack with non-contagious agents details the human body's response to various pathogens, contagious and non-contagious WBA, which are taken into account in the work scenario.

\section{Peculiarities of the biological attack}

The WMD CBRN attack can have catastrophic effects if the military is not properly prepared, trained and equipped. In order to reduce the effects of CBRN agents on the troop, it is necessary for planners/commands to estimate as accurately as possible the total and health 
losses that would occur in different scenarios. Biological attack has its own peculiarities, which differentiate it from other WMDs, but there are also differences between the effect of contagious and non-contagious biological agents involving different military scenarios (Tables no. 2 and 3). (Ordeanu Viorel, 2012).

Table no 2: Essential characteristics of the main non-contagious vs. contagious WBAs (took as a representative example)

\begin{tabular}{|c|l|c|c|c|c|c|l|}
\hline No. & $\begin{array}{c}\text { WBA } \\
\text { weapon }\end{array}$ & Group & Lethal & Contagious & $\begin{array}{c}\text { Prophylaxis } \\
\text { (vaccine) }\end{array}$ & $\begin{array}{c}\text { Specific } \\
\text { treatment }\end{array}$ & Observations \\
\hline 1 & Antrax & bactera & + & - & + & + & \\
\hline 2 & VEE & virus & - & - & - & - & \\
\hline 3 & Botulism & toxin & + & - & - & - & \\
\hline 4 & Pestis & bacterium & + & + & + & + & \\
\hline 5 & Smallpox & virus & + & + & + & - & \\
\hline & index & & 4 & 2 & 3 & 2 & \\
\hline
\end{tabular}

Tabel no 3: The potential use in biological attacks of main noncontagious vs. contagious WBA (taken as representative sample)

\begin{tabular}{|c|l|c|c|c|c|c|c|}
\hline No. & $\begin{array}{c}\text { WBA } \\
\text { weapon }\end{array}$ & Group & Tactic & Operative & Strategic & $\begin{array}{c}\text { Probability } \\
\text { ranking }\end{array}$ & Observations \\
\hline 1 & Antrax & bacterium & + & + & + & $\mathbf{1}$ & \\
\hline 2 & VEE & virus & + & + & - & $\mathbf{5}$ & \\
\hline 3 & Botulism & toxin & + & + & - & $\mathbf{4}$ & \\
\hline 4 & Pestis & bacterium & - & - & + & $\mathbf{2}$ & \\
\hline 5 & Smallpox & virus & - & - & + & $\mathbf{3}$ & \\
\hline & & 3 & 3 & 3 & & \\
\hline
\end{tabular}

Mathematical estimation of human losses caused by biological attack can be achieved by specific methodology, being necessary for medical, logistical, operational and personnel planning. Estimates allow the optimization of medical and non-medical countermeasures to counteract the biological attack and eliminate its consequences.

\section{Mathematical modelling of the epidemics induced by biological attacks with noncontagious agents}

The methodology for estimating the effects of non-contagious WBA attack is based on the scenario that the disease is caused by inhalation of aerosolized WBA. The human response (the body's response) to the biological agent depends on the dose estimate, as with other CBRN agents, and evolves over time with varying degrees of disease severity, specifically with respect to other agents. The calculation is different for non-contagious and contagious agents, in which the contamination is continued by interhuman transmission (from person to person) and is fragmented into specific submodels, so it is more complex. (NATO AMed-8(C), 13-14)

The infectivity sub-model estimates the number of individuals who will be ill after exposure to the agent dose. The (latent) incubation period estimates when individual signs and symptoms will appear.

The mortality sub-model estimates the number of patients who will die. The duration of the disease is estimated with the set of symptoms until healing or death. The disease profile sub-model describes the different clinical stages of the disease and the severity over time (dynamics). 
The body's response to noncontagious diseases is quantified by the number of individuals who will become ill, those who will die, and those who will recover. These values derive from the known parameters of infectivity and mortality known for the respective disease and can be calculated for each military or " $n$ " group (icon):

in $=$ number of individuals in the group

$\mathrm{dn}=$ dose of agent received by each in the group

$\mathrm{pn}=$ efficacy of pre-exposure prophylaxis for the agent, for each group (if not vaccinated the value is 0 )

$\mathrm{pE}(\mathrm{dn})=$ the probability that an individual in group $\mathrm{n}$ will get sick if he receives the dn dose $\operatorname{pf}(\mathrm{dn})=$ the probability that an individual in group $\mathrm{n}$ will die if he receives the $\mathrm{dn}$ dose.

Thus, the distribution and parameters calculated for the probability of illness and/or death are specific to the agent, and individuals receive the same dose and have the same prophylaxis.

The methodology requires that in all diseases with mortality:

[1] $\quad \operatorname{pf}(\mathrm{dn}) \leq \mathrm{pE}(\mathrm{dn})$ for all $\mathrm{n}$

because the number of deaths cannot exceed the number of subjects, and for non-lethal diseases:

[2] $\quad \operatorname{pf}(\mathrm{dn})=0$

for all values of $\mathrm{n}$ and $\mathrm{dn}$, although mortality is not excluded.

The number of individuals in the group which will become ill is:

[3] $\quad$ En $=$ in $\times(1-p n) \times p E(d n)$

The number of dead people is:

[4] Fn $=$ in $\times(1-p n) \times p f(d n) \quad$ where:

$\mathrm{En}=$ number of ill people in $\mathrm{n}$ group,

$\mathrm{Fn}=$ number of dead people in $\mathrm{n}$ group.

The total number of ill people in all groups:

$$
\mathrm{N}
$$

$\mathrm{E}=\Sigma \mathrm{En}$

$\mathrm{n}=1$

Total number of dead people in all the groups:

$$
\mathrm{N}
$$

[6]

$$
\mathrm{F}=\sum \mathrm{Fn}
$$

where $\mathrm{N}=$ total number of groups

Total number of survivors is:

[7] $\mathrm{S}=\mathrm{E}-\mathrm{F} \quad$ where:

$\mathrm{S}=$ number of survivors

$\mathrm{E}=$ number of ill people

$\mathrm{F}=$ number of dead people

All these values are calculated daily for those who show signs of disease according to the degree of severity, according to AMedP-8(C).

\subsection{Anthrax as a biological weapon}

The anthrax bacillus (Bacillus anthracis) is a gram-positive bacillus that sporulates, is found in nature in the soil and can cause diseases in humans and animals (zooanthroponosis): cutaneous, digestive, pulmonary, meningeal and/or septic anthrax, with high lethality. In unfavorable environmental conditions it forms spores (resistance form) with a diameter of approx. $1 \mu \mathrm{m}$, which can survive for decades. So it can be stored like any other ammunition to be used when needed. The spore itself does not produce sickness, because it has no biological activity, but after entering the body it is hydrated, grows, passes into a vegetative form 
(bacterium) that multiplies and secretes toxins, so it provokes complex illness. For operational, technical and medical reasons, bacterium are the favorite biological agent because they are easy to multiply, and among them the spores of Bacillus anthracis are preferred. As proof, the attacks at the beginning of this century were committed with Bacillus anthracis spores. (JAMA. 1999)

It is considered that aerosolization of Bacillus anthracis spores results in an explosive but non-contagious epidemic of anthrax pneumonia. In this way the disease will not spread to the troops, the civilian population or the forces of the attacker, and if it attacks in the place where the front is weakened by illness and death of defenders, there would be no major risk of contamination and infection. Some also consider the aerosolization of pestis bacilli, which causes lung plague, to be a non-contagious disease. From a medical point of view this can only be true from a CBRN point of view. The medical service cannot rely on the assumption that the microbes that cause respiratory diseases are not contagious, it is necessary to apply appropriate countermeasures for the protection of medical staff and other patients. (AmedP-8(C), 2010)

Epidemiologists believe that anthrax has low contagiousness, but patients with lung infection will eliminate microbes through coughing, sneezing, speech, saliva, sputum, bleeding, etc. Around these patients there will be a major risk of air contamination, with a maximum density of up to 1-2 $\mathrm{m}$ and a lower risk of up to 7-8 $\mathrm{m}$ and contact contamination, direct (interhuman) and indirect (through objects and contaminated surfaces). So patients hospitalized for isolation and treatment will contaminate other patients, health care workers and others, including with lung disease, triggering isolated cases of disease or outbreaks. These patients will not cause a secondary epidemic, but are contagious and endanger primarily the medical staff, who must protect themselves properly and apply measures to prevent airborne contamination and contact. The environment will remain persistently contaminated and require special decontamination/disinfection measures. (Ordeanu Viorel, 2012).

The methodology is based on the scenario that the disease is caused by inhalation of Bacillus anthracis spores so it manifests as pulmonary anthrax (inhaler) which in the absence of prophylaxis and treatment has $99 \%$ mortality and the incidence of cutaneous and digestive anthrax (which are treatable) is negligible. This results in an underestimation of the total number of patients. According to the methodology (AmedP-8(C)), pulmonary anthrax is considered to be lethal in all cases, therefore

[8] $\quad \mathrm{E}=\mathrm{F}$ therefore $\mathrm{S}=0$

The WIA calculation estimates the level of severity of the case, the number of patients per day and the inhaled dose of Ba spores:

[9] D antrax n spores UFC (units forming colonies).

It is considered that the minimum dose of spores for an individual's illness is min. 8,000 viable spores (Dembek, Zygmunt F., 2011).

For the DOW calculation, the mortality of $100 \%$ is assumed and the DOW is calculated per day and then the total is made.

Anthrax dose infectivity is modeled as a randomized variable with exponential distribution with the parameter $\lambda(\operatorname{lambda})$ :

$$
-\lambda \mathrm{dn}
$$

[10] PE anthrax $(\mathrm{dn})=1-\mathrm{e} \quad$ where:

$\mathrm{n}=$ number of groups

PE anthrax $(\mathrm{dn})=$ the fraction of personnel exposed to the dose of anthrax that causes the disease

$\mathrm{dn}=$ dose of anthrax spores in the group -5

$\lambda=$ parameter of response-dose $=1.69 \times 10($ AmedP-8(C), A-35 $-\mathrm{A}-36)$

It is considered, based on the known case study, that after inhalation of anthrax spores the disease appears after 1-2 days after high dose (over 1,000,000 spores), at 4-7 days at low 
STRATEGIES XXI International Scientific Conference

The Complex and Dynamic Nature of the Security Environment

dose (10,000 spores), and the danger of illness remains for over 50 days. The disease passes into stage 2 between 3-7 days at high dose and in 9-10 days at low dose, and deaths begin to occur from the second day, with a maximum of 4-7 days at high dose and occur only rarely at low dose, but the risk persists for more than 50 days. The explanation is that some spores can pass late in the vegetative form that causes the disease. As a result, current treatment recommendations EMEA provide antibiotic therapy for 60 days twice a day, both therapeutically and prophylactically after exposure. There are vaccines for human and veterinary use for prophylaxis and if available they protect against disease or reduce the severity of the disease. Post-exposure prophylaxis and treatment are done with antibiotics (preferably fluoroquinolones), but the sensitivity of the bacterium should be checked. Patients should be monitored for at least 60 days, not only for the present infectious disease, but also for relapses as well as for possible side effects of therapy: allergy to antibiotics, side effects of ciprofloxacin, etc. (EMA/CHMP, 2015)

\subsection{Viral encephalitis with $\mathrm{VEE}$ as a biological weapon}

The Venezuelan Equine Encephalitis virus can also infect humans as a non-lethal zooanthroponotic virus, even if it is aerosolized (non-lethal, disabling agent), so theoretically:

[11] $\quad \mathrm{E}=\mathrm{S}$ and $\mathrm{F}=0$

For WIA, the number of patients is multiplied by the values in tables A45 and A46 in AMedP-8(C). For DOW, the value is 0, because VEE exposure does not cause mortality, so it is no longer calculated. Estimated human response to VEE encephalitis input data:

[12] Inhaled dose VEE = DVEE, n UFP (units forming plates).

Infectivity is modeled with a $100 \%$ probability of producing the disease if the dose of 1 UFP is exceeded and mortality is $0 \%$.

Calculation model:

[13] PE VEE $(\mathrm{dn})=1$ for $\mathrm{dn} \geq 1 \mathrm{UFP} \quad$ where: $\mathrm{n}=$ number of groups

PE VEE $(\mathrm{dn})=$ fraction of persons exposed to VEE dose to the place of the group who will get ill (exposed and infected) $\mathrm{dn}=$ VEE dose to the place of the group (UFP), and lethality is assumed as zero $(\mathrm{F}=0)$. (AmedP-8(C), A-50 - A-51)

Diseases occur in the first 4 days, less frequently until day 9 and exceptionally after day 21. The epidemic caused by aerosolization of VEE would be similar to influenza and coronaviruses (example Covid-19), for which we have practical medical experience, as opposed to VEE which is an exotic zooanthroponosis, so almost unknown in Europe. There is no vaccine available and no specific recommended treatment.

\subsection{Botulinium toxin used as biological weapon}

Botulinum toxin is the most toxic substance known and is considered the standard for WBA toxins. In fact, it is a group of 7 protein substances, with variable toxicity, which are biosynthesized by the anaerobic bacterium Clostridium botulinum. Under adverse environmental conditions, this bacterium sporulates and can survive in semi-canned and even canned foods. Once in the body, the spore passes into a vegetative form, multiplies and secretes toxins, which give botulinum intoxication (botulism).

The toxin can be extracted from bacterial cultures, is purified and conditioned as a toxic substance for the production of reagents, drugs and WBA. The presentation of the calculation for botulinum toxin is also a model for the other WBA toxins, which behave similarly to each other and act somewhat similarly to toxic battle substances (WCA). If the toxins are aerosolized, 
after inhalation they reach the airways and enter the bloodstream directly from the lungs, so the effect is faster and stronger than if they were ingested. (JAMA, 2001)

Botulism is a lethal intoxication, with a severity proportional to the absorbed dose, with deaths and survivors, for which the rate of illness per day must be estimated, so:

[14] $\quad \mathrm{S}=\mathrm{E}-\mathrm{F}$

In botulism, the WIA calculation is given by the dose-dependent severity level for survivors and deaths. The first stage is of low and medium severity and the number of patients is calculated by multiplying the values. The second stage is severe, and it is calculated by multiplying the number of patients by the values in table A42 for survivors and A43 for nonsurvivors. For DOW, the values, non-survivors are calculated.

Estimation of the human response to botulism, for input data:

[15] D botulism $n \mu \mathrm{g} / \mathrm{om}$

Botulism diseases are modeled according to log-probit (logarithmic probability) and the median effective dose ED50 $=0.1 \mu \mathrm{g} /$ person, with a logarithmic distribution that cumulates the distribution of CDF functions:

$$
\begin{aligned}
& \text { PE botulism }(\operatorname{dn})=1 / 2+1 / 2\{\operatorname{erf}(\underline{\ln (\operatorname{dn})-\mu})\} \\
& \sigma \sqrt{ } 2
\end{aligned}
$$

where:

$\mathrm{n}=$ number of groups

PE botulism $(\mathrm{dn})=$ fraction of people exposed to the dose and getting ill

$(\mathrm{dn})=$ toxin dose $\mu \mathrm{g} / \mathrm{om}$

$\mu=\log$ natural variable $(\ln 0.1 \mu \mathrm{g} / \mathrm{human}=-2.3026$

$\mathrm{m}=$ probit (logarithmic probability) $\quad 1 / \mathrm{m} \quad 1 / 12.9$

$\sigma=$ standard deviation of natural logarithm e where $=\mathrm{e}=1.0806$

erf = function error, namely:

$$
\operatorname{erf}(x)=2 / \sqrt{ } \pi \int_{0}^{x^{2}} d t^{-t}
$$

Lethality in botulism is given by formulla:

[17] $\quad$ PF botulism $(\operatorname{dn})=1 / 2+1 / 2\{\operatorname{erf}(\underline{\ln (\operatorname{dn})-\mu})\}$

$$
\sigma \sqrt{ } 2
$$

where:

$\mathrm{PF}=$ fraction of people exposed to the dose and dying (percentage mortality). (AmedP-8(C), A-43 - A-49)

The disease appears from the first day (short latency), after 4 days the number of new patients decreases until day 19, but isolated cases can also appear after 21 days. The lethality is high in the first 2-5 days, then decreases to 21 days, after which sporadic deaths can be recorded, for which there is still no physiopathological explanation. There is no vaccine available and no specific recommended treatment.

\section{Conclusions}

In the case of a WMD CBRN attack that also uses biological agents, it is most likely to be used non-contagious WBAs to infect, lethal or non-lethal, as many military personnel as possible, but without creating the risk of contamination for the attacker's troops as well.

Mathematical modeling of the epidemic induced by biological attack (number of sick and dead people) with non-contagious agents is useful for planning the forces and means of medical service, for planning offensive or defensive operation, logistics and human resources needed for support and replacement. The estimates resulting from the calculations according to the formulas recommended in the specific documents allow the optimization of the medical and non-medical countermeasures for the liquidation of the consequences of the biological attack. 
STRATEGIES XXI International Scientific Conference

The Complex and Dynamic Nature of the Security Environment

\section{BIBLIOGRAPHY:}

***, AJP-4 Allied Joint Logistic Doctrine.

***, AJP-4.10 Allied Joint Medical Support Doctrine.

***, AJP-4.10 Allied Joint Medical Support Doctrine.

***, AJP-43 Allied Joint Operation.

***, Concept of operations of medical support in Chemical, Biological, Radiological, and Nuclear environments.

***, EMA/CHMP. 2015. Guidance document on use of medicinal products for the treatment and prophylaxis of biological agents that might be used as weapons of bioterrorism, European Medicines Agency.

***, NATO AMed-8(C), Introduction, 1-18

***, NATO AMedP-8(C), Basis for injury profiles, C-1-95, 2.

***, NATO Planning guide for estimation of CBRN casualties - AmedP-8(C), A-34 - A-42, A-35 - A-36.

***, NATO Planning guide for estimation of CBRN casualties - AmedP-8(C), A-50 - A-51

***, NATO Planning guide for estimation of CBRN casualties - AmedP-8(C), A-43 - A-49

***, North Atlantic Treaty Organization (NATO) Planning Guide for the Estimation of CBRN Casualties- AMedP-8(C). 2010

***, STANAG 2478, Medical support planning for Nuclear, Biological, and Chemical environments.

DEMBEK, Zygmunt F. 2011. USAMRIID's Medical Management of Biological Casualties Handbook, $7^{\text {th }}$ edition. Fort Detrick, Maryland, USA: Army Medical Research Institute for Infectious Diseases (USAMRIID).

JAMA. 2001. "Botulinum toxin as a biological weapon". Consensus statement. Vol. 285, No. 8, February 28, 2001.

ORDEANU V. (coordinator). 2012. Protecţia medicală contra armelor biologice şi a bioterorismului. Bucureşti: MApN CCSMM (In English: Medical protection against biological weapons and bioterrorism).

ORDEANU, V., ANDRIES, A.A., HINCU, L. 2008. Microbiologie și protectie medicala contra armelor biologice" Bucuresti: Ed. Universitara "Carol Davila" (In English: Microbiology and medical protection against biological weapons).

ORDEANU, V., NECSULESCU. M., IONESCU, L.E., POPESCU, D.M., BICHERU, S.N., Dumitrescu, G.V., Hertzog, R.G. 2008. „Anti-infective Therapy Principles in Diseases Caused by Bacterium Biological Agents". Journal of Pharmaceutical Research International, 23, 5 .

ORDEANU, Viorel (coordinator). 2012. Protectia medicala contra armelor biologice (manual pentru pregatire postuniversitara), Bucuresti: Centrul de Cercetari Stiintifice MedicoMilitare (in English: Medical protection against biological weapons (manual for postuniversity education).

ORDEANU, Viorel (coordinator). 2012. Protectia medicala contra armelor biologice vademecum, Bucuresti: Centrul de Cercetari Științifice Medico-Militare (In English: Medical protection against biological weapons - vademecum).

ORDEANU, Viorel, Profesorul Cantacuzino - o carieră de excepţie, Viaţa Medicală, April 2021.The European Agency for the Evaluation of Medicinal Products. 2002 (updated 2007). CPMP/4048/01. EMEA/CPMP Guidance document on use of medicinal products for treatment and prophylaxis of biological agents that might be used as weapons of bioterrorism, London. 